\title{
O PROCESSO DE ALFABETIZAÇÃO EM BRAILLE DA CRIANÇA COM DEFICIÊNCIA VISUAL
}

Éwelyn Inácia de Lima ${ }^{1}$, Jaqueline Batista de Oliveira Costa ${ }^{2}$, Augusta Boa Sorte Oliveira Klebis ${ }^{3}$

${ }^{1}$ Discente do Curso de Pedagogia da Faculdade de Ciências Letras e Educação -UNOESTE - Presidente Prudente. ${ }^{2}$ Docente do Curso de Psicologia da Faculdade de Ciências Humana - Universidade Federal da Grande Dourados/UFGD Dourados/MS. ${ }^{3}$ Docente do Curso de Pedagogia da Faculdade de Ciências Letras e Educação -UNOESTE - Presidente Prudente. E-mail: ewelyn.lima@hotmail.com

\section{RESUMO}

A Educação Especial vem ganhando espaço nos dias atuais. Dentre os alunos que fazem parte desse atendimento encontram-se as crianças cegas, com a necessidade de uma alfabetização diferenciada. Nesse sentido, a presente pesquisa tem como objetivo geral traçar um breve percurso acerca da alfabetização de crianças cegas ao longo da história. Especificamente pretende-se apresentar o uso do sistema braille enquanto importante instrumento de alfabetização das crianças cegas; destacar a necessidade de formação e capacitação docente para alfabetizarem utilizando o sistema alfabético em braile. Esta pesquisa exploratória caracteriza-se como um estudo de caráter qualitativo. Foi realizada a partir de documentos tais como livros, artigos e documentos oficiais. O estudo demonstrou que o sistema braile é o método mais indicado para a alfabetização da criança cega, todavia faz-se necessário que os profissionais da educação estejam capacitados, bem como lacem mão de diferentes estratégias de ensino que garanta a boa qualidade da educação dessas crianças.

Palavras Chave: Educação Especial. Braille. Alfabetização. Deficiência visual. Cegueira.

\section{INTRODUÇÃO E OBJETIVO}

A educação escolar no Brasil, de modo geral, sofreu uma série de transformações nos últimos anos. Tais mudanças afetaram não apenas o ensino oferecido às crianças matriculadas em escolas regulares como, também, a modalidade destinada a crianças com necessidades educacionais especiais atendidas em instituições de ensino especializadas.

Conforme o Artigo 58 da Lei de Diretrizes e Bases da Educação Nacional entendese por educação especial, a modalidade de educação escolar, oferecida preferencialmente na rede regular de ensino, para educandos que apresentem necessidades educacionais especiais. Para tanto, quando necessário, haverá "serviços de apoio especializado, na escola regular, para atender às peculiaridades da clientela de educação especial" (BRASIL, 1996).

Entretanto, "esse atendimento será feito em classes, escolas ou serviços especializados, sempre que, em função das condições específicas dos alunos, não for possível a sua integração nas classes comuns de ensino regular" (BRASIL, 1996).

Os alunos atendidos pela Educação Especial são aqueles que têm impedimentos de longo prazo, de natureza física, mental, intelectual ou sensorial, que em interação com diversas 
barreiras podem ter restringida sua participação plena e efetiva na escola e na sociedade (BRASIL, 2008). Neste grupo está incluso o aluno com cegueira congênita ou adquirida, alvo desse estudo.

Decorrente das inúmeras mudanças que ocorreram no âmbito da educação nacional surge a necessidade de repensar os currículos, os métodos, técnicas, recursos educativos para atender às necessidades educacionais dos alunos cegos. Nesse sentido questiona-se: Que métodos, técnicas e recursos têm sido utilizados ao longo dos anos, pelos professores, na alfabetização de crianças com cegueira na educação especial oferecida em escolas especializadas? Sabe-se que a utilização do alfabeto em braille já é uma realidade comum em muitas escolas especializadas para crianças cegas, todavia as escolas encontram-se equipadas com recursos materiais, humanos e pedagógicos para atender a essa clientela e oferecer-Ihes uma educação de boa qualidade? Os professores estão capacitados para alfabetizarem este grupo de crianças? $E$, se estão como se dá o processo de alfabetização da criança cega? Quais os principais desafios, dificuldades e avanços encontrados por estes professores alfabetizadores? Esta e outras questões delimitam o escopo dessa pesquisa.

Esta pesquisa justifica-se devido à constatação, durante o estágio realizado em escolas de ensino regular que atendem crianças cegas, de que os professores demonstram dificuldades na alfabetização destes alunos. Alguns contam com poucos recursos técnicos ou pedagógicos, fato que inviabiliza a aquisição do domínio da leitura e da escrita pelas crianças cegas. Bem sabemos que os estímulos sociais e familiares dados às crianças cegas são precários e isto dificulta a aquisição do sistema alfabético braille. Consequentemente impede a formação de conceitos básicos, prejudicando, assim, o seu desenvolvimento cognitivo.

Nesse sentido, a presente pesquisa tem como objetivo geral traçar um breve percurso acerca do processo de alfabetização de crianças cegas ao longo da história. Especificamente pretende-se apresentar o uso do sistema braille enquanto importante instrumento de alfabetização das crianças cegas; destacar a necessidade de formação e capacitação docente para alfabetizarem utilizando o sistema alfabético em braille.

\section{METODOLOGIA}

A presente pesquisa exploratória caracteriza-se como um estudo de caráter qualitativo-descritivo. Segundo Lüdke e André (1986), na pesquisa qualitativa grande parte dos dados coletados é de natureza descritiva. Nessa modalidade de estudo a preocupação com o 
processo é maior do que com o produto, e o pesquisador direciona um olhar especial ao modo das pessoas veem a vida, entre outras coisas.

Cervo e Bervian (1983) destacam ainda que as pesquisas descritivas têm como objetivo primordial à descrição das características de determinada população ou fenômeno, no caso deste estudo o fenômeno a ser descrito é o processo de alfabetização de crianças cegas ao longo da história.

O projeto de pesquisa foi cadastrado no Programa de Iniciação Cientifica - PEIC - da Universidade do Oeste Paulista/UNOESTE (protocolo: 1614) e recebeu parecer favorável. A pesquisa completa será realizada em duas etapas distintas: documental/bibliográfica e de campo, porém neste trabalho será apresentado apenas os dados referentes à primeira etapa: pesquisa documental/bibliográfica. Para localização do material bibliográfico utilizou-se os seguintes descritores: educação especial; braille; deficiência visual; cegueira e alfabetização. Foram também consultados documentos como a Lei de Diretrizes e Bases da Educação Nacional (Lei 9394/96). Os dados bibliográficos, após coletados e reunidos receberam tratamento analítico descritivo.

\section{RESULTADOS}

\subsection{A Deficiência Visual e Educação Especial: Um Breve Histórico}

Para entender como se iniciou o processo de implantação da modalidade Educação Especial, é importante primeiro traçar uma breve linha histórica sobre como as pessoas com deficiência eram vistas e tratadas ao longo da história da humanidade.

$\mathrm{Na}$ antiguidade era muito comum que as crianças que nascessem com alguma deficiência ou doença fossem executadas. Isso acontecia em diversas regiões, e poderia ser por decisão do estado ou da família, dependendo das regras admitidas na sociedade.

Já na Idade Média os deficientes foram acolhidos pelo cristianismo, ganhando abrigo e cuidados, já que essa doutrina condenava a execução dessas pessoas (EMMEL, 2002 apud SILVA, 2010). Foi neste período que surgiu o primeiro hospital para cegos, em Paris, destinado aos cuidados com soldados que haviam perdido a visão em batalha. Porém, apesar de serem acolhidos, os deficientes da época eram apresentados como culpados pela própria deficiência, já que essa condição era tida como um castigo de Deus, devido aos pecados (PESOTTI, 1984 apud SILVA, 2010).

Com o avanço de pesquisas sobre o corpo humano, em especial do cérebro, uma nova concepção começou a ser formulada a respeito das deficiências. É a partir do século XVI que 
então se iniciou o movimento de Educação Especial, com o surgimento de algumas instituições especializadas e de novas teorias. Entre essas instituições é importante destacar o Instituto Nacional dos Jovens Cegos.

Quadro 01. A Educação da Criança Cega

\begin{tabular}{|c|c|c|}
\hline Período histórico & Como o Cego era visto & Educação oferecida \\
\hline Antiguidade & $\begin{array}{l}\text { Não se enquadrava nos } \\
\text { moldes de "ser humano" e } \\
\text { por } \begin{array}{ll}\text { isso era } \\
\text { executado/escondido. }\end{array}\end{array}$ & $\begin{array}{l}\text { Não havia atenção voltada às } \\
\text { pessoas com deficiência e } \\
\text { sua educação. }\end{array}$ \\
\hline Idade média & $\begin{array}{l}\text { Acolhidos pela sociedade } \\
\text { cristã, mas como alvo de } \\
\text { pena. }\end{array}$ & $\begin{array}{l}\text { Oferecidos cuidados aos } \\
\text { cegos, mas ainda sem olhar } \\
\text { voltado à sua educação. }\end{array}$ \\
\hline Século XVI e XVII & $\begin{array}{l}\text { Passou a ser alvo de estudos } \\
\text { iniciais que traziam pequenas } \\
\text { mudanças nas concepções } \\
\text { que se tinha acerca dessas } \\
\text { pessoas. }\end{array}$ & $\begin{array}{l}\text { Inicia-se o movimento da } \\
\text { Educação Especial. }\end{array}$ \\
\hline Séculos XVIII XIX e XX & $\begin{array}{l}\text { Passa a ser estudada em seu } \\
\text { desenvolvimento cognitivo, } \\
\text { motor, sensorial, etc. }\end{array}$ & $\begin{array}{l}\text { Educação Especial acontece } \\
\text { inicialmente em escolas } \\
\text { especializadas, como o } \\
\text { Instituto Nacional dos Jovens } \\
\text { Cegos de Paris (século XVIII). }\end{array}$ \\
\hline Século XVI & $\begin{array}{l}\text { É admitido na sociedade com } \\
\text { suas necessidades e } \\
\text { características específicas. }\end{array}$ & $\begin{array}{l}\text { Educação Especial ainda em } \\
\text { escolas especializadas, } \\
\text { porém também com } \\
\text { disseminação de sua inclusão } \\
\text { na escola regular. }\end{array}$ \\
\hline
\end{tabular}

Fonte: As autoras, com base na revisão bibliográfica realizada.

No Brasil, entre o fim do século XVIII e o início do século XIX é que os princípios liberais começaram a influenciar no surgimento da Educação Especial (JANNUZZI, 2004 apud SILVA, 2010). Segundo Silva (2010) o primeiro passo que levou à garantia dos direitos dos cegos no Brasil foi a criação do Imperial Instituto dos Meninos Cegos, criado por Dom Pedro II, em 1854. Em 1891 o nome do instituto mudou para Instituto Benjamin Constant (IBC), em homenagem ao seu terceiro diretor, como é conhecido até os dias atuais.

Sobre a importância do IBC, Bruno e Mota (2001, p. 27) destacam que: “(...) foi o primeiro educandário para cegos na América Latina e é a única Instituição Federal de ensino destinada a promover a educação das pessoas cegas e das portadoras de baixa visão no Brasil". 
Assim, com a instalação dessa intuição, além de outras, e também com a Declaração Universal dos Direitos Humanos e a LDBEN - Lei de Diretrizes e Bases par Educação Nacional de 1961, é que emerge no Brasil a preocupação com a Educação Especial e a inclusão. Com isso a escola brasileira está sendo reestruturada: os espaços físicos estão sendo adaptados e os profissionais envolvidos sendo preparados para o atendimento à criança cega. Para essa preparação o mínimo de informações é essencial, já que segundo Krick e Zych (2009) não é difícil deparar-se com educadores que frente à uma criança cega não sabem como agir.

\section{2 A criança cega, o sistema braille e a alfabetização}

A criança com deficiência visual congênita, ou adquirida logo no início da vida estabelece relação com o mundo a sua volta diferente da maneira que acontece com as crianças que enxergam. Isso porque conforme destaca Sá, Campos e Silva (2007) cerca de $80 \%$ dos estímulos enviados pelo ambiente, são captados por meio da visão. Para Amiralian (1997, p. 21) "esta condição imposta pela ausência da visão se traduz em um peculiar processo perceptivo, que se reflete na estruturação cognitiva e na organização e constituição do sujeito psicológico".

Para Laplane e Batista (2008, p. 210) "a cegueira ocorre quando a visão varia de zero (ausência de percepção de luminosidade) a um décimo na escala optométrica de Snellen, ou quando o campo visual é reduzido a um ângulo menor que 20 graus". Porém de acordo com Defendi (2011, p. 9) “A pessoa cega é aquela que tem uma perda total ou resíduo mínimo de visão que a leva a necessitar do Sistema Braille como meio de leitura e escrita".

Logo, percebemos que Laplane e Batista (2008) enfatizam uma definição legal de cegueira, enquanto Defendi (2011) emprega-a no campo educacional. Isso se faz necessário devido à complexidade dos comprometimentos que essa pessoa pode apresentar, especialmente no processo de aprendizagem escolar. No presente estudo será adotada a definição trazida por Defendi (2011), para que seja possível focalizar o processo de alfabetização das crianças cegas que fazem uso do sistema braille.

É importante relembrar que, nem toda pessoa com deficiência visual precisa fazer uso do sistema braille para escrita e leitura, apenas as pessoas cegas. Desfaz-se, assim, a crença de que o braille deva ser utilizado por todos os deficientes visuais, até porque apenas cerca de 10 a 15\% das pessoas com deficiência visual podem ser consideradas realmente cegas (DEFENDI, 2011). Para Mosquera (2010), o braille cumpre a função social de qualquer escrita: transmitir 
informações. E é por isso que se torna o método mais adequado às pessoas cegas, pois possibilita que esta leia o que escreveu.

$\mathrm{Na}$ sociedade, as crianças videntes se deparam cotidianamente com elementos estimuladores à sua alfabetização. Isso ocorre, por exemplo, quando elas observam um outdoor ou folheiam uma revista (KRICK E ZYCH, 2009). Ao contrário dessas, as crianças cegas não têm o estimulo do ambiente com relação à escrita e leitura, porque o braille não faz parte do cotidiano socialmente estabelecido. Esse obstáculo pode resultar em prejuízos e atrasos no processo de alfabetização (BRUNO e MOTA, 2001). Nesse caso, segundo Krick e Zych (2009) observa-se uma desvantagem, já que este estímulo não acontecerá de forma tão aleatória, sendo necessária a apresentação por meio da utilização dos outros sentidos, de maneira mais específica. A desvantagem se acentua ainda mais quando isso só passa a acontecer com seu ingresso no ensino fundamental.

A cela braille é composta por duas colunas com três pontos cada. As combinações destes pontos formam 63 sinais básicos que representam as letras, os números e outros símbolos, como de pontuação e notas musicais (SÁ; CAMPOS; SILVA, 2007).

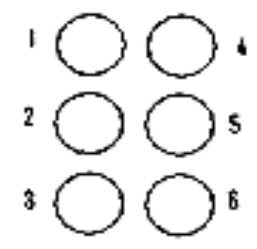

Figura 01. A cela braile

Fonte: Sá; Campos; Silva, 2007.

A leitura do braille é feita com os dedos das duas mãos, percorrendo os pontos da esquerda para a direita. Já a escrita pode ser desempenhada por meio de uma reglete e punção, ou da máquina de escrever braille. Na cela braille a coluna da esquerda possui os pontos 1, 2 e 3, e a da direita os pontos 4, 5 e 6 . Na escrita com a reglete a cela é invertida, para produzir os pontos em relevo na ordem da leitura. (MOSQUERA, 2010).Já na máquina de escrever braille a escrita é feita na mesma direção da leitura, proporcionando mais agilidade e facilidade na compressão dos símbolos.

Geralmente durante esse processo de alfabetização em específico, o método sintético, também chamado de fonético, é o mais aplicado. Isto porque ele possibilita uma íntima relação entre o símbolo da escrita e a sua representação oral. Porém isso não é determinante, 
como ressalta Mosquera (2010, p. 84): “Qualquer método pode ser usado, desde que respeitem as necessidades de compreensão da natureza perceptivo-tátil e não visual adotada no ensino de crianças deficientes visuais."

Em suma, o braille oferece ao cego a possibilidade de acesso ao conhecimento, e se este for alcançado o objetivo está sendo cumprido. Assim, para que o aluno cego não perca o interesse e a motivação no ambiente escolar é muito importante fornecer recursos que favoreçam os seus outros sentidos (SÁ; CAMPOS; SILVA, 2007. Deste modo, acima de tudo é importante lembrar que o educando cego tem tanto potencial para aprender quanto os outros, e sendo assim os procedimentos e materiais devem ser bem adaptados e adequados a eles, para possibilitar que o desenvolvimento de suas habilidades ocorra.

\section{DISCUSSÃO}

Levando-se em conta a história que a educação de cegos traçou é possível observar que houve inúmeros avanços que possibilitaram a sua inclusão em uma sociedade repleta de informações, relações e conhecimento. Dentre essas, sem dúvida a invenção do método braille merece destaque pela importância que representa no desenvolvimento das pessoas com cegueira.

O processo de alfabetização de crianças cegas possui várias características peculiares por se tratar de algo que envolve muitos aspectos diferenciados, desde o uso de um alfabeto reproduzido em relevo e códigos distintos, até a adequação minuciosa de um contexto alfabetizador. Para impedir que estas crianças tenham sua aprendizagem prejudicada é necessário investir em materiais e métodos que atendam as reais necessidades do educando com cegueira. É necessário ainda investir na formação do docente alfabetizador de modo que este profissional possa refletir sobre sua prática e oferecer a este grupo de alunos uma educação de boa qualidade.

Visando essa formação o MEC oferece materiais de orientação sobre a deficiência visual e os assuntos que a cercam como a socialização da criança cega, sua orientação e mobilidade, e claro, sua escolarização e alfabetização. É possível ainda encontrar vários materiais de orientação publicados por instituições como o IBC e a Fundação Dorina Nowill.

Enfim, com a crescente presença de alunos cegos tanto nas escolas especiais como nas escolas de ensino regular, também cresce a possibilidade de capacitação nesta área, que todos os docentes devem direcionar um pouco de atenção, pois graças aos princípios de inclusão, qualquer um pode ter uma criança cega em sua sala de aula. 


\section{CONCLUSÃO}

A presença de estudantes cegos é uma realidade que merece atenção. A melhor forma de contribuir com a educação dessas crianças é investir em capacitação para os profissionais da área. Estudos como este contribuem para a disseminação desses conhecimentos entre a comunidade, que necessita estar atenta, em busca de melhorias no meio da educação especial.

\section{REFERÊNCIAS}

AMIRALIAN, M. L. T. M. Compreendendo o cego: uma visão psicanalítica da cegueira por meio de Desenhos-Estórias. São Paulo: Casa do Psicólogo, 1997.

BRASIL. Ministério de Educação e Cultura. Lei de Diretrizes e Bases da Educação Nacional. Lei 9394, 20 de dezembro de 1996.

BRASIL, Ministério da Educação - Secretaria de Educação Especial (SEESP). Política nacional de educação especial na perspectiva da educação inclusiva. Brasília: MEC, 2008.

BRUNO, M. M. G; MOTA, M. G. B. Programa de Capacitação de Recursos Humanos do Ensino Fundamental: deficiência visual vol.1. Fascículos I - II - III. Brasília: Ministério da Educação, Secretaria de Educação Especial, 2001. Disponível em: <http://portal.mec.gov.br/seesp/arquivos/pdf/def_visual_1.pdf> Acesso em: 08 abr. 2013

BRUNO, M. M. G; MOTA, M. G. B. (coord.) Programa de Capacitação de Recursos Humanos do Ensino Fundamental: deficiência visual vol. 2. Fascículo IV. Brasília: Ministério da Educação, Secretaria de Educação Especial, 2001. Disponível em: <http://deficienciavisual6.com.sapo.pt/xtxt-DeficienciaVisual-MarildaBruno-MGloriaMota-2.pdf> Acesso em: 08 abr. 2013

CERVO, Amado L. e BERVIAN, Pedro A. Metodologia Científica: para uso dos estudantes universitários. 3.ed. São Paulo: McGraw-Hill do Brasil, 1983.

DEFENDI, Edson Luiz. O livro, a leitura e a pessoa com deficiência visual. São Paulo: Fundação Dorina Nowill para Cegos, 2011.

KRICK, Lucicléia; ZYCH, Anizia Costa. Alfabetização do educando cego: um estudo de caso. In: Congresso Nacional de Educação, 9., Encontro Sul Brasileiro de Psicologia, 3., 2009, Curitiba. $\begin{array}{lllll}\text { Anais... } & \text { Curitiba: } & \text { PUCPR, } & 2009 . & \text { P. }\end{array}$ Disponívelem:<http://www.pucpr.br/eventos/educere/educere2009/anais/pdf/3258_1559.pdf>. Acesso em: 14 mar. 2013.

LAPLANE, A. L. F. de; BATISTA, C. G. Ver, não ver e aprender: a participação de crianças com baixa visão e cegueira na escola. Cad. Cedes, Campinas, v. 28, n. 75, p. 209-227, maio/ago., 2008. Disponível em:<http://www.scielo.br/pdf/ccedes/v28n75/v28n75a05.pdf>. Acesso em: 14 mar. 2013. 
Encontro de Ensino, Pesquisa e Extensão, Presidente Prudente, 21 a 24 de outubro, 2013

LÜDKE, Menga e ANDRÉ, Marli E. D. A. Pesquisa em educação: abordagens qualitativas. São Paulo: EPU, 1986.

MOSQUERA, C. F. F. Deficiência visual na escola inclusiva. Curitiba: Ibpex, 2010.

SÁ, E. D. de; CAMPOS, I. M. de; SILVA, M. B. C. Deficiência Visual. São Paulo: MEC/SEESP, 2007.

SILVA, A. M. da. Educação especial e inclusão escolar: história e fundamentos. Curitiba: Ibpex, 2010. 